\title{
O envolvimento do enfermeiro no processo de morrer de bebês internados em Unidade Neonatal
}

\author{
Nurses experiences with death in the neonatal intensive care unit \\ El involucramiento del enfermero en el proceso de morir de niños hospitalizados en una unidad de \\ neonatología
}

\section{Isabella Rocha Aguiar1, Tatiana Maria Coelho Veloso' ${ }^{2}$, Ana Karina Bezerra Pinheiro $^{3}$, Lorena Barbosa Ximenes ${ }^{4}$}

\begin{abstract}
RESUMO
Objetivo: compreender a participação do enfermeiro no processo de morrer de bebês internados em unidade de terapia intensiva neonatal. Métodos: Pesquisa Qualitativa em que participaram 10 enfermeiras de uma unidade de terapia intensiva neonatológica de um hospitalescola da cidade de Fortaleza-CE, durante os meses de maio e junho de 2003. Resultados: os resultados foram analisados conforme as categorias: Sentimentos que emergem na convivência com a morte; Convivendo com a família no processo de morrer; A influência da formação acadêmica para a convivência com o paciente terminal. Os sentimentos citados foram de perda, tristeza, angústia, impotência, frieza. Os profissionais se vêem envolvidos com a família que vivencia o luto. A maioria das enfermeiras não teve embasamento acerca de Tanatologia no Curso de Graduação. Conclusão: os profissionais que lidam com a morte em sua prática convivem com a busca do equilíbrio entre o cuidar do outro e de si mesmo.
\end{abstract}

Descritores: Atitude frente a morte; Tanatologia; Terapia intensiva neonatal; Pesar; Relações profissional-família

\begin{abstract}
Objective: to understand Neonatal Intensive Care nurses experiences caring for dying neonates. Methods: this was an qualitative exploratory study. Ten Neonatal Intensive Care Unit nurses from a school-affiliated hospital in Fortaleza, Ceará participated in this study. Data were collected during May and June, 2003.Results: the following categories emerged from the analysis: feelings in the presence of death; interacting with the family in the process of dying; and, educational inadequacies coping with a terminally ill neonate. The feelings expressed by the nurses included loss, sadness, misery, weakness, and detachment. The nurses also see themselves involved with the grieving family, although the majority of them reported not having enough foundational knowledge with grief and thanatology. Conclusion: those nurses who deal with death in the workplace, such as the Neonatal Intensive Care Unit, are trying to keep a balance between caring for others and themselves.
\end{abstract}

Keywords: Attitude to death; Thanatology; Intensive care neonatal; Grief; Professional-family relations

\author{
RESUMEN \\ Objetivo: comprender la participación del enfermero en el proceso de morir de bebés internados en una unidad de cuidados intensivos \\ neonatal. Metodos: Pesquisa Qualitativa en que participaron en el estudio 10 enfermeras de la unidad de cuidados intensivos neonatal de un \\ hospital-docente de la ciudad de Fortaleza-CE, durante los meses de mayo a junio del 2003. Resultados: los datos fueron analizados \\ resultando las siguientes categorías: Sentimientos que emergen en la convivencia con la muerte; Conviviendo con la familia en el proceso de \\ morir; La influencia de la formación académica para la convivencia con el paciente terminal. Los sentimientos citados fueron de pérdida, \\ tristeza, angustia, impotencia, frialdad. Los profesionales se ven involucrados con la familia que vivencia el duelo. La mayoría de las \\ enfermeras no tuvo base respecto a Tanatología en el Pregrado. Conclusión: los profesionales que se enfrentan con la muerte, en su práctica, \\ conviven con la búsqueda del equilibrio entre el cuidar del otro y de sí mismo. \\ Desciptors: Actitud Frente a la muert; Tanatología; Cuidado intensivo neonatal; Pesar; Relaciones profesional-familia \\ ${ }^{1}$ Acadêmica do 80 semestre do Curso de Graduação de Enfermagem da Universidade Federal do Ceará - UFC - Fortalez̧a (CE), Brasil; \\ ${ }^{2}$.Enfermeira graduada pela Universidade Federal do Ceará - UFC - Fortaleza (CE), Brasil. \\ ${ }^{3}$.Doutora em Enfermagem; Professora Adjunto I do Departamento de Enfermagem da Faculdade de Enfermagem da Universidade Federal do Ceará - UFC \\ - Fortaleza (CE), Brasil; Co-tutora do Programa de Educação Tutorial (PET). \\ ${ }^{4}$.Doutora em Enfermagem; Professora Adjunto I do Departamento de Enfermagem da Faculdade de Enfermagem da Universidade Federal do Ceará - UFC \\ - Fortaleza (CE), Brasil;
}




\section{INTRODUÇÃO}

No decorrer da história, as enfermeiras eram mulheres que prestavam assistência de forma direta ao paciente, que se dedicavam ao ofício de realizar partos, limpeza de feridas e administração de poções. Em 1860, Florence Nightingale, após reduzir consideravelmente a mortalidade nos hospitais militares na Guerra da Criméia, conduziu a prática e a formação do profissional de Enfermagem ${ }^{(1)}$.

A Enfermagem é uma profissão que lida com o ser humano, interage com ele e requer o conhecimento de sua natureza física, social e psicológica ${ }^{(1)}$. Desta forma, o cuidar pode ser caracterizado pela atenção, zelo e preocupação com o outro.

O cuidar está inserido desde o nascer até o morrer. A finalidade desta ação implica aliviar, ajudar, pois a cura não é o fim, devendo estar presente até mesmo no processo de morrer.

No entanto, a formação acadêmica pode deixar lacunas e o profissional é impulsionado a acreditar que somente a cura e o restabelecimento são características de um bom cuidado. Os hospitais e sua tecnologia, a dinâmica da luta incessante pela vida não permitem nem abrem espaços para questionar, conversar e pensar na morte.

A morte perturba a paz hospitalar e os profissionais acabam por comentarem os êxitos e os cuidados com bons resultados. Para eles, frutos de uma formação que ressalta a onipotência e eficiência, encarar a morte é aceitar o fracasso e perder para a doença, é algo difícil de ser vivenciado $^{(2)}$.

Apesar dos enormes avanços tecnológicos e terapêuticos em saúde, usualmente os profissionais não estão preparados para atender pessoas em processo de morte, bem como em lidar com seus sentimentos e emoções em tal contexto(3).

Falar da morte, abstrata ou específica, de alguém ou da nossa, é falar do que se está fazendo, do que não se fez, de planos, sonhos, perdas, do tempo que se foi, do que ainda resta; é disso que fugimos e tememos enfrentar ${ }^{(4)}$.

A morte do outro é uma lembrança da própria morte, e nisto consiste a dificuldade das pessoas em dar àqueles que morrem a ajuda e afeição de que necessitam, ao se despedir dos outros ${ }^{(5)}$.

O século XX nos traz a morte que se esconde, a morte vergonhosa. A sociedade atual expulsou a morte para proteger a vida. Já não há sinais de que uma morte ocorreu. A característica deste século é dar a impressão de que nada mudou, a morte não deve ser percebida. A morte já não é um fenômeno natural e, sim, fracasso, impotência, imperícia e por isso deve ser ocultada ${ }^{(6)}$.

A morte deixa de ser no lar e passa a acontecer nas indiferentes enfermarias. Os profissionais buscam, então, aterem-se à área orgânica do paciente, apegam-se a valores numéricos e a defesa contra a dor e o fracasso se instrumentaliza em ação imediata e compulsiva: ligar aparelhos, fazer massagens cardíacas, entubar. Eles querem desvendar os segredos do corpo humano abalado pela enfermidade, vencer a morte, ou, no mínimo, controlá-la, adiando-a ${ }^{(7)}$.

Se a morte é encarada como um tabu horrendo, medonho, jamais chegaremos a afrontá-la com calma ao ajudar um paciente ${ }^{(8)}$. Se os profissionais não percebem a morte com serenidade, como podem pretender ajudar o paciente que busca vivenciar uma boa morte, que espera deles respostas ou palavras que os façam se sentir melhores?

Surge, então, a necessidade desses profissionais quebrarem o silêncio e ousarem falar de suas dores, medos, do luto que deve ser elaborado, a fim de que suas demandas sejam atendidas e melhor cuidado seja oferecido. É importante que eles se permitam entristecer e não se sintam culpados $^{()^{)}}$.

Apesar da supressão do luto com a negação dos sinais de morte e os fatores sócio-culturais implicados, as pessoas devem ser estimuladas a dividir os sentimentos relacionados à perda e ao luto a fim de evitar implicações psíquicas futuramente.

Além disso, o assistir não acaba com a morte do paciente. É responsabilidade do enfermeiro prestar cuidados aos que vivenciam o luto. Esse processo é necessário e penoso diante da morte de um ente querido, onde se revê conceitos sobre a existência, a vida e a morte, a fim de que possa, em cada situação, agir de forma adequada e humanizada.

Diante disso, o enfermeiro inserido em Unidade de Terapia Intensiva Neonatológica (UTIN) convive diariamente com a situação de morte iminente do recémnascido $(\mathrm{RN})$, e com a presença constante dos pais que reconhecem a fragilidade da situação de seu filho correlacionando a questão da UTIN e morte, o que pode implicar diretamente na conduta deste profissional, dificultando o modo de atuar diante da morte que se torna tão evidente para todos.

Perante esta realidade, fizemos a seguinte questão norteadora: Como será que os profissionais de Enfermagem de UTI- Neonatológica têm experienciado o processo do morrer dos recém-nascidos?

Não só na UTI-Neonatológica, mas da obstetrícia à geriatria, o profissional de enfermagem se percebe envolvido nas questões referidas, o quê só vem a justificar a importância de pesquisar acerca da temática. Procurando conhecer como o profissional de enfermagem lida com a situação iminente da morte de seus pacientes e os sentimentos que emergem na convivência direta com a morte, poderemos obter uma compreensão mais holística do comportamento humano, levando os enfermeiros, docentes e mesmo os próprios discentes de Enfermagem 
a refletirem sobre a sua prática, procurando experienciar esta fase da existência humana de forma significativa.

Objetivo

- Compreender a participação do enfermeiro no processo de morrer de bebês internados em uma unidade de terapia intensiva neonatal;

\section{METODOS}

A pesquisa foi descritiva, que é uma investigação empírica que visa explorar a realidade, descrevendo seus fatos ou fenômenos com exatidão ${ }^{(10)}$.

Participaram da pesquisa 10 enfermeiras assistenciais de uma UTIN de um hospital-escola da cidade de Fortaleza-CE. A escolha se deu pelo fato dos profissionais de enfermagem que se encontram neste tipo de unidade conviverem diariamente com a condição grave dos pacientes que necessitam de cuidados, sendo mais freqüentes questionamentos acerca da vida e da morte. Sendo assim, foram selecionadas as enfermeiras que trabalhavam no setor, independente do tempo de atuação na UTIN, que aceitassem participar da pesquisa, após a explanação do objetivo, assinando, o Termo de Consentimento Livre e Esclarecido pós-informação, conforme a Resolução n 196/96 do Conselho Nacional de Saúde, sendo-lhes garantidos o anonimato, a liberdade de desistir da pesquisa a qualquer momento, e o livre acesso ao conteúdo, sendo identificadas por meio de letras.

Após aprovação da solicitação à instituição hospitalar, o projeto foi e aprovado pelo Comitê de Ética em Pesquisa do Complexo Hospitalar da Universidade Federal do Ceará, para, então, iniciarmos a coleta de dados.

Foi uma pesquisa de campo, por meio de encontros individuais durante os meses de maio e junho de 2003, a partir de entrevista semi-estruturada, utilizando um roteiro abordando aspectos inerentes à experiência do profissional ao lidar com a morte, o qual pode ser considerado como facilitador de abertura e aprofundamento da comunicação ${ }^{(11)}$.

Após a coleta, os dados foram organizados e discutidos de forma sistemática, obedecendo as fases de análise de Martins e Bicudo ${ }^{(12)}$. Foi realizada transcrição das entrevistas gravadas e leitura do material coletado com a finalidade de se familiarizar com o conteúdo dos discursos, identificando as unidades de significado. Posteriormente, procedemos à síntese, agrupando as unidades que expressavam os mesmos significados e sentidos, procurando a convergência das descrições, chegando à construção de três categorias, sendo então, estas discutidas de acordo com a literatura pertinente.

\section{RESULTADOS}

Em seguida, serão apresentadas as falas mais significativas das enfermeiras, sendo agrupadas segundo as categorias que emergiram.

Sentimentos que emergem na Convivência com a Morte ... Impotência

"A gente se sente impotente, sofre mais pelo fracasso de saber que a gente não conseguiu" $(\mathrm{E})$

"Será que eu fiz o possivel? Será que eu não podia fazer um pouquinho mais?" (H)

"Há um sentimento de impotência, porque você tenta fažer tudo pra salvar e, às vezes, não consegue"'(G)

"A gente sente aquela coisa, pôxa, aquele paciente que eu cuidei foi à óbito" (D)

\section{... Tristeza}

"Eu sinto aquela tristeza, até lágrimas, às vezes, a gente chora porque infelizmente a gente se envolve mesmo" $(D)$

"A morte não deixa de ser tristeza, saudade, perda..."(B)

"Sinto angústia, decepção... (silêncio)"(H)

"Quando a gente se envolve com o paciente na hora o sentimento é de perda"(E)

\section{... Envolvimento}

"Como eu trabalho com recém-nascido, quando me envolvo, acabo me emocionando e afetando meu trabalho" (J)

"Com certeza adentra minha vida pessoal" $(A)$

"Tem bebês que passam muito tempo aqui, você se apega, é muito difícil, realmente eu não gosto muito de falar sobre a morte" $(C)$

"...quando o bebê apenas piorava eu não conseguia me controlar emocionalmente"(E)

"O que eu procuro sempre é colocar meus filhos na situação" $(H)$

"Vez. ou outra eu ligo: Como é que tá, o bebê melhorou? Não, faleceu? Apesar do tempo, eu não consegui fazer essa desvinculação. Eu acho necessária, mas não me prejudica sabe?"(A).

"Eu não tenho medo jamais de expor as minhas emocões, acho que a enfermeira deve se envolver, sem medo, de coração" $(H)$.

"Se você vai tratar pensando em não se envolver, você não vai tratar como um ser bumano, que necessita do teu cuidado, do teu carinho" $(A)$.

\section{... Indiferença}

"Eu acabei chegando a conclusão que eu me manter a distância, não me envolver tanto era necessário ou ia acabar em frangalhos" (E)

"Às vezes, o bebê chora a noite toda... entra por um ouvido e sai por outro, a morte passa do mesmo jeito; o bebê acaba de ir à óbito e a gente vê profissionais conversando sobre a vida alheia e rindo, contando piada"(J)

"Quando eu envolvo, acabo me emocionando e afetando meu trabalho"(J)

"Frieza, porque o trabalho da gente é fazer o procedimento" $(D)$

"Toda vez que morrer um paciente, se a gente for se desgastar emocionalmente(...) ai a gente acaba criando uma capazinha dura para se proteger, frieza." $(\mathrm{E})$

... Apego

"Às vezes o apego maior écom bebê que já está aqui há meses"(E)

"A gente se apega, porque aqui eles demoram muito, a gente vê eles evoluindo satisfatoriamente, faz tudo para tentar melhorar"(I)

... Alívio 
"Se for uma criança que realmente já está se arrastando, é um alivio. Tem bebês que é aquela morte surpresa, que você se choca, você se doou tanto na assistência..."(B)

"Quando é um paciente que chegou a morte e ele estava bem, você se lamenta, começa a procurar as interrogações e os porquês" (D)

"Se o bebê tá muito grave, sofrendo, pra gente é um alivio, a gente encara como uma coisa boa pra ele... Se é um bebê que vem bem e de repente piora, a gente fica arrasada"(E)

\section{... Preocupação com o corpo após a morte}

"Eu procuro deixar arrumadinho, de forma que a mãe quando chega não veja que o bebê ficou tão sofrido, né, eu tento arrumar, as mãozinhas póstumas, tento fechar a boquinha." (A)

"Deixo ele com a melhor aparência possivel, para que a família não entre em choque quando veja"(I)

Convivendo com a Família no Processo de Morrer

\section{... Estabelecendo vínculos}

"Quando ela chega e vê o bebezinho, não tem como conter as lágrimas, você chora com ela, vive aquela hora de sofrimento. Tem que conversar, sofrer junto, faz.parte do nosso dia-a-dia" $(A)$

“É importante estar presente, dar apoio, o principal é ouvir." $(H)$

\section{... Dificuldade de estabelecer vínculos}

"A gente precisa preparar a mãe, mas não temos tempo de trabalhar todas, né? É muito duro dizer assim: mãe seu filho morreu"(D)

"Eu não minto, eu digo: a senhora sabe que seu bebê tá muito grave... É muito difícil dar uma noticia dessas"( $G)$.

\section{... Proporcionando conforto à família}

"Quando acontece comigo de um bebê ir à óbito, principalmente um que a mãe nunca acarinhou, retiro tudo e pergunto se ela quer colocá-lo no colo, se quer ficar um tempo com ele, ela tem o direito de ter o sentimento daquele luto." $(H)$

Influência da Formação Acadêmica para a Convivência com o Paciente Terminal

\section{... Lacuna na formação universitária}

"Na faculdade a gente comenta raramente sobre como vocêpode abordar a familia na hora que o paciente morre... Senti necessidade de fazer um curso extra-curricular (E)

"A gente aprende a preparar o corpo na universidade, mas não tem uma abordagem sobre a morte, como é lidar com isso. A gente não sai preparado, apesar de saber que vai lidar com estas situações, que faz.parte da nossa vivência” $(F)$

\section{... Percebendo a necessidade de uma melhor}

\section{formação}

"Senti necessidade de fazer um curso extra-curricular, pra mim foi muito bom...Seria necessário realmente na faculdade ter uma disciplina sobre isso" (E)

"Não teve nada na minha formação acadêmica. É importante que tivesse algo na academia. A gente foi vivenciar a morte já com a morte mesmo. A vida continua, o trabalho tem que continuar, não tem preocupação na faculdade nem no ambiente de trabalho." (B)

"Não teve nada sobre isso onde me formei. Acho necessário." (A)

... Distância entre teoria e prática

"A minha formação não influencia quanto a esse aspecto. Por mais que se fale em uma sala de aula sobre morte é inexplicável, é muito diferente no dia-a-dia as situações que você encontra... A teoria é importante, mas certas coisas na vida você tem que vivenciar"( $C)$.

\section{DISCUSSÃO}

A morte ainda é muito estigmatizada na sociedade e conviver diretamente com ela causa um grande mal-estar nas pessoas, ocorrendo até mesmo nos profissionais que vivenciam o processo de morrer constantemente ${ }^{(13)}$.

Todos os esforços da sociedade atual parecem estar dirigidos a ocultar a morte. A sociedade dicotomizou os fenômenos da morte e da vida, que sempre caminharam juntos até que a técnica surpreendeu com a ilusão de que a vida pode ser estendida infinitamente. Assim, os hospitais tornaram-se um lugar para ocultar a morte, transformando-a de fato natural a artificial ${ }^{(14)}$.

Dificuldades profissionais e pessoais acabam por interferir na assistência prestada, pois fazem emergir alguns sentimentos como a frustração, a sensação de fracasso, a impotência, a incapacidade, que impedem o profissional de enfermagem de exercer o seu adequado papel, no sentido de atender às necessidades básicas do enfermo e sua família nos seus aspectos biopsicossociais.

A equipe de enfermagem é a que passa mais tempo com o paciente e que primeiro atende às suas necessidades ${ }^{(2)}$.

É relevante identificar os sentimentos vivenciados na prática dos enfermeiros, afinal é sabido que o autoconhecimento é um processo importante a ser explorado a fim de melhor lidar com situações que impliquem manifestação de emoções profundas, principalmente as relacionadas com a morte.

Os profissionais são seres humanos e não podem isolar suas emoções do trabalho; o modo de separá-los consiste na habilidade de reconhecer os próprios sentimentos ${ }^{(15)}$.

Quanto às enfermeiras pesquisadas, os sentimentos citados foram de perda, tristeza, angústia, impotência, frieza, que descrevem, na verdade, a situação da nossa sociedade que, excluindo a dor e a morte, considera-as como fracasso e erro.

Há presente também a vivência da impotência e angústia frente à situação irreversível. A sensação de impotência surge em conseqüência da própria formação direcionada a recuperar a vida. A perda do controle da situação, a iminência da morte, apesar de todos os recursos tecnológicos, faz com que os profissionais encarem suas limitações. Ao reconhecê-las, é como se a habilidade profissional estivesse sendo testada, como se a manutenção da vida dependesse da competência da equipe responsável pelo paciente.

A relação desses profissionais com a morte é uma relação de angústia, visto que está associada a uma experiência de temor interiorizado, que no hospital é a 
possibilidade de morte que se confronta com a fantasia onipotente da imortalidade ${ }^{(16)}$.

É primordial que o profissional de saúde reveja seus conceitos sobre a existência, se assim não o fizer, permanecerá encarando a morte dos pacientes como fracasso, impotência, frustração $o^{(4)}$.

Outros sentimentos citados pelas entrevistadas foram de perda e saudade, que estão relacionados com o envolvimento com os bebês, pelo fato das enfermeiras se empenharem e investirem muito na recuperação, acompanhando a gradual evolução do recém-nascido, que permanece muito tempo na unidade (3-4 meses).

Dessa forma, esse envolvimento pode levar a uma desorientação e/ou descontrole no momento da morte do neonato, pois um vínculo é rompido. Algumas entrevistadas citaram que passam a enxergar aquele paciente como se fosse um ente da família, ou o próprio filho, repercutindo assim na assistência prestada e interferindo na rotina desses profissionais mesmo fora do ambiente hospitalar.

Alguns profissionais consideraram o envolvimento com o paciente intrínseco ao cuidado, não apenas necessário, mas determinante do tipo de assistência a ser oferecida. Ao compreender a essência do outro, na sua vida e morte, passa a compreender-se e a explicar a trajetória pessoal no ato e na arte de cuidar de seres no seu existir ${ }^{(17)}$.

Contudo, evidenciou-se que é importante cada profissional perceber o seu limite a fim de não se prejudicar nem diminuir o desempenho profissional. Existe uma cultura no meio hospitalar de que o bom profissional de enfermagem não deve se envolver ${ }^{(16)}$.

Percebeu-se que o tempo de convivência com o paciente determinará um luto diferenciado. O luto é um processo necessário e penoso, tido como um sentimento de pesar e dor diante da morte de quem se $\mathrm{ama}^{18}$. A morte de uma pessoa que já se tornara querida na enfermaria pode abalar profundamente aqueles profissionais mais dedicados ${ }^{(19)}$.

O luto consiste na manifestação pública de sentimentos e pensamentos expressos e compartilhados com os que o cercam, é o processo de adaptação social que tende a reestruturar a vida dos que vivenciaram uma perda ${ }^{(5)}$.

Determinadas situações foram descritas como sendo o óbito um alívio e outras em que é uma surpresa. Para os profissionais, a morte súbita é mais difícil de ser elaborada, pois a sensação é de que poderiam ter feito mais. Por isso, o paciente que morre aos poucos, dá a oportunidade ao enfermeiro de vivenciar esta perda como se ele tivesse feito o possível pelo paciente ${ }^{(16)}$.

A morte súbita traz insegurança para muitos, pois é uma morte que acontece de repente e, se aconteceu com o paciente pode acontecer com qualquer um, inclusive com o próprio profissional ${ }^{(16)}$.
Outro sentimento muito citado pelas participantes foi a tristeza. A tristeza é definida como qualidade ou estado do triste; falta de alegria; pena, desalento, aflição, e triste pode ser definido como magoado, cheio de melancolia, infeliz; abatido, deprimido ${ }^{(20)}$. Os profissionais costumam sentir tristeza após a morte de seus pacientes devido à sensação de perda e vazio.

Apesar da tristeza e impotência expressada após o óbito do paciente, o convívio diário com o morrer pode fazer os profissionais encararem com naturalidade, ou ainda frieza, indiferença. A tentativa de se protegerem e não vivenciarem sentimentos os quais poderiam desestabilizá-los, podem prejudicar a dinâmica hospitalar. Buscam, então, isolar seus medos e angústias a fim de conseguir trabalhar em um ambiente como o hospital ${ }^{(16)}$.

Existe, no ambiente hospitalar, uma certa "regra" que diz que o bom profissional não deve se envolver. Desta forma, não encontrando espaço para expressar sua angústia e fraqueza, o profissional nega e encobre seus sentimentos. Percebe-se a necessidade dessas profissionais de desenvolver mecanismos de defesa, como manter a distância, manifestar comportamento de frieza frente às situações ou ainda um aparente equilíbrio, na tentativa de manejar de forma mais adequada a situação.

Nas instituições de saúde propaga-se um comportamento considerado "ideal" àquele em que o profissional não se envolve, não encontra espaço para expressar sua angústia e fraqueza. Percebe-se um discurso institucional que, em nome do profissionalismo, estimula a impessoalidade e tenta distanciar quem trabalha dos principais fatos que configuram a realidade, a dor, o sofrimento, a morte ${ }^{(7)}$.

Outra questão ressaltada, de grande importância para a prática hospitalar, foi o cuidado com o corpo após a morte. Foi percebido, como parte de um cuidado humanizado, a preocupação com o estado do corpo do bebê após o óbito, além da busca de oferecer a melhor assistência possível.

Entretanto, em uma unidade de neonatologia, o paciente não se resume somente ao recém-nascido, mas à sua família, e de forma especial, à mãe.

Não há dúvida de que chegar a ter um filho representa a máxima realização de uma pessoa ${ }^{(21)}$. Os profissionais se vêem envolvidos com a família que passa pelo processo penoso e necessário do luto e sentem a necessidade de oferecer apoio, permanecer próximo a fim de acolher a mãe no momento difícil que ela vivencia.

Os profissionais de saúde, especialmente os enfermeiros, por sua maior proximidade com os familiares, têm a difícil responsabilidade de preparar a mãe para o prognóstico, muitas vezes não satisfatório, do seu filho. Informar quanto ao estado do bebê, preparandoa para o enfrentamento do luto ou até mesmo dar a notícia do falecimento são atitudes esperadas e necessárias que o enfermeiro desempenhe. Escolher ser enfermeiro implica 
no desejo de estar sempre próximo ao sofrimento e à morte, situações temidas pelo ser humano ${ }^{(15)}$.

A finalidade do cuidado na Enfermagem é prioritariamente aliviar o sofrimento humano, manter a dignidade e facilitar meios para manejar com as crises e com as experiências do viver e do morrer ${ }^{(1)}$.

Verificou-se, portanto, que mesmo diante da situação de luto e pesar, as enfermeiras adequaram a assistência, priorizando o cuidado aos enlutados, permitindo que os familiares ficassem um tempo com seu filho.

Muitos profissionais sentem-se despreparados para lidar com situações que implicam na morte, em decorrência, muitas vezes, da falta de reflexão e total silêncio, por parte da universidade, que se detém no tecnicismo, deixando que a vivência da prática os conduza a descobrir o que é importante nesse processo.

É sabido que os currículos dos cursos de Enfermagem são incrementados de disciplinas sobre fundamentos e teorias de Enfermagem, formando pessoas aptas a cuidar e prolongar a vida, porém bem pouco preparadas a assistir pacientes fora de possibilidade terapêutica. Os currículos mais atuais e inseridos dentro de uma perspectiva antropológica e psicológica valorizam disciplinas e momentos em que o aluno, com suas questões pessoais, possa ter espaço para manifestar seus princípios a fim de amadurecer a visão da realidade.

A maioria dos enfermeiras pesquisadas não teve embasamento teórico nem vivência durante a faculdade acerca de Tanatologia: das dez entrevistadas, apenas uma delas relatou ter tido uma disciplina que abordou o tema "morte"; refletindo, posteriormente, a necessidade de fazer cursos extra-curriculares.

É necessário que os cursos de graduação promovam discussões sobre o tema, sobre a assistência de enfermagem ao paciente em fase terminal. Todas as entrevistadas relataram a importância de aprofundar o tema "morte" nas faculdades.

Já alguns profissionais percebem uma considerável distância do aprendizado teórico para o prático no que se refere à luto e morte.

É importante uma reformulação dos currículos dos cursos de Enfermagem para que sejam inseridos momentos de vivência e reflexão acerca da perda e luto a fim de que os profissionais não se sintam desamparados ao lidarem com a realidade hospitalar, a qual necessariamente exigirá deles uma postura livre de tabus e participativa numa relação de ajuda e cuidado.

\section{CONCLUSÃO}

Verificou-se que, durante a participação das enfermeiras no processo de morrer de seus pacientes, emergiram sentimentos, como: impotência, angústia, frieza, tristeza, saudade; que, por um lado, interferiram na assistência prestada ao enfermo e sua família; mas por outro, mostraram que, apesar da vivência constante com a morte na sua prática hospitalar, as enfermeiras ainda se sensibilizam com o processo. Os profissionais que lidam com a morte em sua prática, o fazem de forma dolorosa e convivem com a busca do equilíbrio entre o cuidar do outro e de si mesmo. Observou-se também que há uma preocupação constante com a família, sendo esta valorizada e inserida no contexto hospitalar e de cuidado do próprio filho.

Quanto à formação acadêmica das entrevistadas, concluiu-se que a maioria não teve o preparo acadêmico que permitisse lidar de forma adequada com a morte de seus pacientes, tornando-as despreparadas psicologicamente para esse tipo de situação. Dessa maneira, fazse necessário que os cursos de graduação incluam momentos de vivência e reflexão acerca da perda e do luto, a fim de melhor preparar os profissionais de enfermagem.

Além disso, é necessário oportunizar situações que auxiliem os profissionais de enfermagem a utilizarem mecanismos de enfrentamento satisfatórios diante da morte. A construção de um atendimento individual e grupal com todos os profissionais de saúde, oportunizando um ambiente que vislumbre o diálogo aberto para expressarem suas angústias, receios, medos, dentre outros sentimentos que exacerbam em suas vidas, não só profissionais como pessoais, de forma a ajudálos a desenvolver a arte de conviver com a morte e o luto.

Assim, é preciso que os enfermeiros chorem suas perdas; propiciem um tempo distante da unidade de prestação de cuidado; utilizem técnicas grupais para encerrar e lamentar a perda de um cliente, pois se o luto não for aliviado, assim como o estresse, pode implicar na diminuição do bem-estar e à incapacidade de cuidar de outros ${ }^{(22)}$.

\section{REFERÊNCIAS}

1- Waldow VR. Cuidado humano: o resgate necessário. 2a ed. Porto Alegre: Sagra Luzzatto; 1999.

2- Figueiredo RM. A enfermagem diante do paciente com AIDS e a morte [tese]. Campinas: UNICAMP; 1994. 144p.

3- Balsanelli AP, Santos KJ, Soler ZOSG. O trabalho do enfermeiro em unidades complexas: um enfoque sobre os sentimentos para o cuidado diário de pacientes com risco de morte. Nursing (São Paulo). 2002; 5(44): 23-8.

4 Angerami VA (Organizador). E a psicologia entrou no hospital... São Paulo: Pioneira; 1996.

5- Bellato R, Carvalho EC. O jogo existencial e a ritualização da morte. Rev Latinoam Enfermagem. 2005; 13(1):99-104.

6- Kovács MJ. Pensando a morte e a formação de profissionais de saúde. In: Cassorla RMS, Coordenador. Da morte: estudos brasileiros. Campinas: Papirus Editora; 1991.p. 80-2. 
7- Oba MDV, Tavares MSG, Oliveira MHP. A morte mediante as representações sociais dos profissionais de saúde. Rev Bras Enfermagem. 2002; 55(1):26-30.

8- Kubler-Ross E. Sobre a morte e o morrer. 3a ed. São Paulo: Martins Fontes; 1987.

9- Worden JW. Terapia do luto: um manual parao profissional de saúde mental. Porto Alegre: Artes Médicas; 1998.

10- Leopardi MT. Fundamentos gerais da produção científica. In: Leopardi MT. Metodologia da pesquisa na saúde. Rio Grande do Sul: Editora Pallotti; 2001. p. 126 -75.

11- Minayo MCS. O desafio do conhecimento: pesquisa qualitativa em saúde. 3 a ed. São Paulo: Hucitec-Abrasco; 1994.

12- Martins J, Bicudo MAV. A pesquisa qualitativa em psicologia: fundamentos e recursos básicos. 2a ed . São Paulo: Moraes; 1994.

13- Popim RC, Barbieri A. O significado da morte perinatal: depoimentos de mães. Rev Bras Enfermagem. 1990; 43(1/4): 134-40.

14- Leis HR. A sociedade dos vivos. Sociologias. 2003; 5(9):
340-53.

15- Leoni MG. Autoconhecimento do enfermeiro na relação terapêutica. Rio de Janeiro: Cultura Médica; 1996.

16- Martins EL, Alves RN, Godoy SAF. Reações e sentimentos do profissional de enfermagem diante da morte. Rev Bras Enfermagem. 1999; 52(1):105-17.

17- Castro DSP, Pokladek DD, Ázar FP, Piccino JD, Josgrilberg RS, organizador. Existência e saúde. São Bernardo do Campo: UMESP; 2002.

18- Loureiro MFF. O sentido do comportamento materno diante da morte do filho. Fortaleza: UFC; 1998.

19- Botega NJ, organizador. Prática psiquiátrica no hospital geral: interconsulta e emergência. Porto Alegre: Artmed; 2002.

20- Ferreira ABH. Novo dicionário da língua portuguesa. $2^{\mathrm{a}}$ ed., rev. e aum. Rio de Janeiro: Nova Fronteira; c1986.

21- Knobel M. Orientação familiar. 2a ed. Campinas: Papirus; 1996.

22- Potter PA, Perry AG. Fundamentos de enfermagem: conceitos, processo e prática. 4a ed. Rio de Janeiro: Guanabara Koogan; 1999. v. 1. 